\title{
Usulan Penentuan Harga HRC dengan Simulasi Sistem Dinamis di PT. KS
}

\author{
Nunung Nurhasanah ${ }^{1 *}$, Luhur Anggito ${ }^{2}$ \\ ${ }^{1}$ Program Studi Teknik Industri, Fakultas Sains dan Teknologi, University Al Azhar Indonesia, \\ Jl.Sisingamangaraja, Jakarta 12110 \\ ${ }^{2}$ Jurusan Teknik Industri, Fakultas Sains dan Teknologi, Universitas Bina Nusantara, \\ Jl. KH. Syahdan no.9, Kemanggisan, Jakarta 11480
}

*Penulis untuk korespondensi: nunungnurhasanah@uai.ac.id

Abstrak - Perkembangan pasar global yang fluktuatif semakin menuntut perusahaan seperti PT. KS untuk dapat mangambil keputusan yang tepat dan cepat. Salah satu produk dari PT. KS adalah hot rolled coil (HRC), produk dari PT. KS dijual dengan menggunakan harga yang bersifat dinamis dan mengikuti kondisi harga yang terjadi secara internasional karena produk yang dijual sudah menjadi produk komoditas. Untuk itu, PT. KS membutuhkan suatu sistem yang dapat mendukung proses pengambilan keputusan dalam menentukan harga dari produk HRC. Dalam penelitian ini digunakan metode-metode seperti peramalan, technical analysis, dan simulasi. Metode peramalan digunakan untuk memprakirakan kondisi harga HRC yang akan terjadi di Internasional. Metode technical analysis digunakan untuk memperkirakan kecenderungan trend yang akan terjadi pada harga HRC internasional. Dan metode simulasi digunakan untuk memprakirakan kondisi harga HRC yang akan terjadi di Internasional dengan mempertimbangkan faktor-faktor yang mempengaruhi perubahan dari harga HRC.

Abstract- Fluctuation of the global market growth demanding the company like PT. KS to make the right and fast decision. One of the PT. KS's product is hot rolled coil (HRC), the price of this product is a dynamic price, which is following the trail of the international price condition because this product can be classified as a commodity product. Therefore, PT. KS needs a system that can help the company to support the decision taking for HRC product. In this research, we use some of the method like forecasting method, technical analysis, and simulation technique to estimate the price condition of HRC product. Forecasting method is used for estimating the price condition of HRC product internationally. Technical analysis is used for estimating the trend tendency that will occur. And simulation method is used for estimating the price condition of HRC product internationally which can be calculated with the judgemental decision by decision maker. From these methods, we analyze the method that can be a basis for HRC price decision.

Keyword - forecasting, system, simulation, HRC, price

\section{PENDAHULUAN PENDAHULUAN}

$\mathrm{P}$ ada era globalisasi saat ini, pertumbuhan industri dunia yang mencapai sekitar 5\% pertumbuhan tiap tahunnya [1] menunjukkan bahwa industri berkembang dengan sangat pesat. Hal ini disebabkan karena semakin tingginya permintaan akan suatu produk demi memenuhi kebutuhan hidup manusia yang ditandai oleh nilai GDP dunia sebesar $\$ 60-\$ 70$ triliun per tahun [1].

Oleh karena itu, banyak industri yang tumbuh dan bersaing untuk memperoleh pasar yang lebih luas dengan memanfaatkan keunggulan yang dimilikinya. Dengan persaingan yang semakin tinggi dalam dunia usaha, banyak pengusaha yang berusaha untuk mempertahankan perusahaannya agar dapat tetap hidup dalam jangka waktu yang lama dan dapat terus berkembang serta meningkatkan keuntungan perusahaannya.

Perkembangan pasar global yang fluktuatif semakin menuntut perusahaan-perusahaan untuk dapat 
menciptakan keputusan yang tepat dan cepat. Ketepatan waktu dalam membuat keputusan adalah suatu hal yang sangat penting. Keputusankeputusan yang baik membutuhkan pertimbangan dan analisa yang baik untuk memastikan agar keputusan yang dipilih merupakan keputusan yang tepat. Dan keputusan-keputusan ini juga harus dilaksanakan dengan cepat. Sehingga dapat menghasilkan keputusan yang efektif.

Kemampuan perusahaan-perusahaan untuk memprakirakan kondisi yang akan datang menjadi salah satu kunci utama untuk memperoleh keuntungan dan juga untuk mempertahankan keberadaan serta menumbuhkembangkan perusahaan. Hal tersebut berlaku pula pada pasar baja saat ini yang sudah menjadi komoditas yang tidak sedikit pula dipengaruhi oleh keadaan pasar global.

Perusahaan yang menjadi objek penelitian adalah PT. KS. PT. KS merupakan suatu perusahaan BUMN (Badan Usaha Milik Negara) yang didirikan pada tahun 1970 dan terletak di daerah Cilegon, Banten, yang bergerak di bidang produksi baja untuk melayani permintaan baja di dalam negeri (nasional) maupun di luar negeri (internasional).

PT. KS memproduksi produk-produk baja seperti lembaran baja panas (hot rolled coil), lembaran baja dingin (cold rolled coil), dan batang kawat (wire rod). Produk-produk baja produksi PT. KS tersebut banyak digunakan untuk kebutuhan otomotif, pembuatan pipa atau tabung, pembuatan kawat dan paku, konstruksi kapal, dan lain-lain.

PT. KS yang merupakan sebuah perusahaan baja, di mana baja sudah menjadi produk komoditas yang pastinya kondisi pasar baja global akan memiliki dampak terhadap PT. KS. Kemampuan untuk memprakirakan kondisi baja global menjadi salah satu kunci utama bagi PT. KS dalam mempertahankankan usahanya. Dengan mengetahui prakiraan kondisi baja global, maka PT. KS dapat mengambil kebijakan-kebijakan yang tepat dalam menghadapi kondisi yang akan terjadi.

Di antara produk-produk PT. KS, produk hot rolled coil (HRC) merupakan produk yang memiliki kapasitas produksi yang paling tinggi yaitu sebesar 2 juta ton kapasitas pertahun di mana untuk produkproduknya seperti cold rolled coil (CRC) dan wire rod memiliki kapasitas produksi sebesar 700.000 ton per tahun untuk CRC dan 400.000 ton per tahun untuk wire rod.

Dengan kapasitas produksi HRC yang sebesar 2 juta ton per tahun maka produk HRC memiliki pengaruh yang paling besar terhadap keuntungan maupun kerugian yang dialami oleh PT. KS. Maka dari itu, produk HRC merupakan pilihan kami dalam tinjauan penelitian.

Untuk produk HRC, PT. KS menerapkan sistem job order, maksudnya barang diproduksi bila sudah terjadi pemesanan oleh konsumen yang ditandai dengan adanya perjanjian kontrak jual beli. Kontrak jual beli tersebut akan mengikat apabila sudah ada jaminan uang cash senilai 30\% untuk konsumen baru dan $10 \%$ untuk konsumen lama yang memiliki rating yang baik. Sisa pembayaran akan dilakukan dengan menggunakan LC (letter of credit), di mana LC tersebut harus sudah diterima sebelum barang diproduksi (dilakukan pengerolan).

Mengingat waktu mulai dari pemesanan sampai produk jadi dan siap dikirim mencapai kurang lebih 2 bulan, maka peramalan sangat dibutuhkan dalam penentuan harga dasar HRC di PT. KS.

PT. KS pernah mengalami pengurangan keuntungan yang cukup besar pada tahun 2005. Pada tahun 2008 juga terjadi pengurangan keuntungan dan berlanjut sampai dengan bulan Juli 2009 yang disebabkan karena stok bahan baku dan barang jadi dengan harga yang lama belum terjual. Pada saat itu harga yang tadinya melambung naik tiba-tiba mengalami penurunan harga yang cukup drastis, sehingga PT. KS menanggung pengurangan keuntungan yang cukup besar.

Salah satu sebab dari hal ini adalah harga yang ditetapkan tidak sesuai dengan keadaan yang terjadi. Pada saat harga mengalami penurunan drastis PT. KS tetap menetapkan harga yang tinggi, yang berakibat pada tidak terjualnya produk-produk PT. KS. Dalam kasus ini PT. KS belum memiliki sistem yang standar untuk memperkirakan/ meramalkan perubahan harga yang akan terjadi.

Adapun masalah-masalah yang dihadapi oleh PT. KS adalah metode apa yang sesuai digunakan untuk menganalisa harga dasar hot rolled coil (HRC) agar dapat diperoleh suatu analisa yang dapat mendukung pengambilan keputusan, berapa prakiraan harga dasar HRC internasional untuk bulan Januari, Februari, dan Maret 2010, bagaimana trend yang akan terjadi pada harga dasar 
HRC internasional untuk awal tahun 2010 dan faktor-faktor apa saja yang mempunyai pengaruh besar dalam perubahan harga dasar HRC.

Tujuan dari penelitian ini adalah memberikan suatu analisis harga agar dapat digunakan untuk mempertimbangkan keputusan, memberikan panduan dalam penentuan harga dasar HRC agar pengambil keputusan, dalam hal ini pihak direksi tidak terlalu subyektif atau mengurangi pengaruh psokologis dan menentukan faktor-faktor penting yang mempengaruhi perubahan harga dasar HRC internasional.

\section{TINJAUAN PUSTAKA}

Peramalan adalah seni dan ilmu untuk memprediksi masa depan. Peramalan merupakan tahap awal, dan hasil ramalan merupakan basis bagi seluruh tahapan pada perencanaan produksi. Pada penelitian ini, jenis peramalan yang dilakukan adalah peramalan metode kuantitatif [2].

Metode peramalan kuantitatif yang digunakan adalah Regresi linier, Double moving average, Double exponential smoothing Brown, Double exponential smoothing Holt dan Triple Exponential smoothing Brown. Pemilihan metode peramalan terbaik akan menggunakan pendekatan Mean Absolute Percentrage Error (MAPE).

Simulasi merupakan suatu penyelesaian atau perhitungan tahap demi tahap dari persamaan matematika yang menggambarkan keadaan sistem untuk mengetahui perubahan yang terjadi pada sistem tersebut sehingga diketahui perilakunya [3].

Simulasi didefinisikan pula sebagai peniruan perilaku suatu gejala atau proses. Simulasi bertujuan untuk memahami gejala atau proses tersebut, membuat analisis dan peramalan perilaku gejala atau proses tersebut di masa depan [4].

Simulasi merupakan salah satu alat analisis yang terpercaya bagi perancangan dan pengoperasian proses atau sistem yang rumit. Dengan semakin meningkatnya persaingan dunia, simulasi menjadi alat yang sangat cocok untuk perencanaan, perancangan dan pengawasan bagi sebuah sistem. Simulasi merupakan sebuah tiruan dari sebuah cara operasi di dunia nyata.

Model simulasi adalah suatu teknik dimana hubungan sebab akibat dari suatu sistem ditangkap (capture) di dalam sebuah model komputer, untuk menghasilkan beberapa perilaku sesuai dengan sistem nyata.

Pelaksanaan simulasi melalui 4 tahap, dimana tahap pertama simulasi adalah penyusunan konsep. Gejala atau proses yang akan ditirukan perlu dipahami, antara lain dengan menentukan unsurunsur yang berperan dalam gejala atau proses tersebut.

Tahap kedua adalah pembuatan dan perumusan model. Konsep pada tahap awal dirumuskan sebagai model yang berbentuk uraian gambar atau rumus.

Tahap ketiga, simulasi dapat dilakukan dengan menggunakan model yang telah dibuat. Dalam model kuantitatif, simulasi dilakukan dengan memasukkan data ke dalam model, dimana perhitungan dilakukan untuk mengetahui perilaku gejala atau proses. Dalam model kualitatif, simulasi dilakukan dengan menelusuri dan mengadakan analisis hubungan sebab akibat antar unsur dengan memasukkan data atau informasi yang dikumpulkan untuk mengetahui perilaku gejala atau proses.

Tahap terakhir, dilakukan validasi untuk mengetahui kesesuaian antara hasil simulasi dengan gejala atau proses yang ditirukan. Model dapat dinyatakan baik apabila kesalahan atau simpangan hasil simulasi terhadap gejala atau proses yang ditirukan kecil. Hasil simulasi tersebut selanjutnya digunakan untuk memahami perilaku gejala atau proses serta mengetahui kecenderungannya di masa mendatang [5].

Penelitian terdahulu yang pernah dilakukan membahas mengenai penggunaan model sistem dinamik untuk menganalisis pengaruh sumberdaya finansial dalam penelitian bisnis dan ekonomi [6].

\section{METODOLOGI PENELITIAN}

Sesuai tujuan akhir yang hendak dicapai dalam penelitian ini adalah untuk memberikan usulan penentuan harga dengan simulasi sistem dinamis. Sehingga, dalam penelitian ini diawali dengan memperkirakan kecenderungan trend harga dengan pendekatan forecasting, kemudian dilakukan simulasi sistem dinamis, dan hasil simulasi diuji dengan pendekatan U-Theil. Diagram alir metodologi penelitian disajikan pada Gambar 1 . 


\section{HASIL DAN PEMBAHASAN}

Pada tiap-tiap metode perhitungan peramalan diperoleh hasil peramalan yang berbeda-beda. Misalnya, pada peramalan dengan menggunakan metode regresi linier diperoleh hasil peramalan yang cenderung meningkat di mana hal ini disebabkan oleh proyeksi keseluruhan kecenderungan peningkatan harga yang meningkat.

Peramalan dengan menggunakan metode double moving average menghasilkan hasil peramalan yang memiliki kecenderungan menurun. Peramalan dengan menggunakan metode double exponential smoothing Brown, double exponential smoothing Holt, dan triple exponential smoothing Brown menghasilkan hasil peramalan yang cenderung mendatar, dari metode-metode peramalan ini hanya terdapat sedikit perbedaan.

Pada tabel perbandingan MAPE dapat ditunjukkan bahwa metode yang memiliki MAPE terbesar dalam kasus ini adalah metode regresi linier, yangdilanjutkan dengan metode double moving average. Metode pemulusan seperti metode double exponential smoothing Brown, double exponential smoothing Holt, dan triple exponential smoothing Brown memiliki nilai MAPE pada kisaran 6-7\%.

Pada metode double exponential smoothing Brown diperoleh MAPE sebesar $6.070 \%$, pada metode double exponential smoothing Holt diperoleh MAPE sebesar $6.018 \%$, dan pada metode triple exponential smoothing Brown diperoleh MAPE sebesar $7.372 \%$.

Berdasarkan hasil dari peramalan yang dilakukan, dapat disimpulkan bahwa metode yang memiliki nilai MAPE yang cenderung lebih kecil adalah metode pemulusan seperti metode double exponential smoothing Brown, double exponential smoothing Holt, dan triple exponential smoothing Brown. Di mana metode-metode peramalan cukup sesuai dalam penggunaannya dalam meramalkan harga dasar HRC internasional dalam jangka pendek. Hasil peramalan dan perbandingan nilai penyimpangan hasil peramalan masing-masing disajikan pada Tabel 1 dan 2.

Pada grafik yang dihasilkan dari metode moving average convergence divergence dapat ditunjukkan oscillator yang terdapat baik pada grafik MACD maupun dalam grafik MACD histogram.
Tabel 1. Perbandingan MAPE

\begin{tabular}{lc}
\hline \multicolumn{1}{c}{ Metode Peramalan } & MAPE (\%) \\
\hline Regresi linier & 20.223 \\
Double moving average & 10.897 \\
Double exponential smoothing Brown & 6.070 \\
Double exponential smoothing Holt & 6.018 \\
Triple exponential smoothing Brown & 7.372 \\
\hline
\end{tabular}

Tabel 2. Perbandingan Hasil Peramalan

\begin{tabular}{lccc}
\hline \multirow{2}{*}{ Metode Peramalan } & \multicolumn{3}{c}{ Peramalan (US\$/Ton) } \\
\cline { 2 - 4 } & $\begin{array}{c}\text { Januari } \\
\mathbf{2 0 1 0}\end{array}$ & $\begin{array}{c}\text { Februari } \\
\mathbf{2 0 1 0}\end{array}$ & $\begin{array}{c}\text { Maret } \\
\mathbf{2 0 1 0}\end{array}$ \\
\hline Regresi linier & 655.264 & 657.804 & 660.345 \\
$\begin{array}{l}\text { Double moving average } \\
\begin{array}{l}\text { Double exponential } \\
\text { smoothing Brown }\end{array}\end{array}$ & 488.000 & 474.000 & 460.000 \\
$\begin{array}{l}\text { Double exponential } \\
\text { smoothing Holt }\end{array}$ & 514.480 & 513.975 & 513.471 \\
$\begin{array}{l}\text { Triple exponential } \\
\text { smoothing Brown }\end{array}$ & 514.453 & 513.911 & 513.369 \\
\hline
\end{tabular}

Pada grafik MACD histogram untuk periode Oktober 2008 dapat dilihat terjadi perubahan nilai MACD histogram dimana yang tadinya bernilai positif pada periode September 2008 menjadi bernilai negatif pada Oktober 2008.

Perubahan ini dapat juga dilihat dalam grafik MACD pada Oktober 2008 di mana garis MACD menembus ke bawah garis signal yang menandakan bahwa harga akan naik. Gambar yang menunjukkan plot dari harga dasar HRC internasional dan harga dasar HRC PT. KS dapat ditunjukkan pada gambar di bawah berikut.

Pada gambar grafik harga dasar HRC internasional, untuk bulan Oktober 2008 memang terlihat suatu penurunan harga yang cukup tajam di mana sebelumnya mulai dari awal tahun 2008 terjadi peningkatan sampai bulan Juni-Juli 2008.

Pada gambar grafik harga dasar HRC PT. KS juga dapat dilihat bahwa sampai pada bulan Oktober 2008 PT. KS tetap menetapkan harga yang tinggi, hal ini yang menyebabkan berkurangnya konsumen yang membeli produk HRC pada PT. KS saat bulan-bulan tersebut. PT. KS baru menurunkan harganya setelah bulan Oktober 2008, yaitu pada bulan November 2008 yang pada saat itu harga 
dasar HRC internasional berada pada titik harga yang paling rendah di tahun 2008 sebesar US $\$ 485$ di mana pada bulan November 2008 PT. Krakatau Stel menentukan harga sebesar US\$1093 .

Dalam grafik MACD dapat dilihat bahwa pada bulan Oktober 2008 grafik MACD mengindikasikan akan terjadinya penurunan harga. Namun, dengan membandingkan antara pergerakan harga dasar HRC internasional dengan grafik MACD tersebut, grafik MACD terlihat sedikit terlambat dimana penurunan harga dasar HRC internasional mulai merosot tajam pada bulan Agustus 2008.

Pada kondisi bulan Desember 2010, grafik MACD atau MACD histogram tidak menunjukkan adanya indikasi perubahan harga yang berarti. Dimana dalam grafik MACD tidak terjadi perpotongan garis MACD dengan garis signal, atau dalam grafik MACD histogram tidak terjadi perubahan nilai dari positif ke negatif atau sebaliknya.

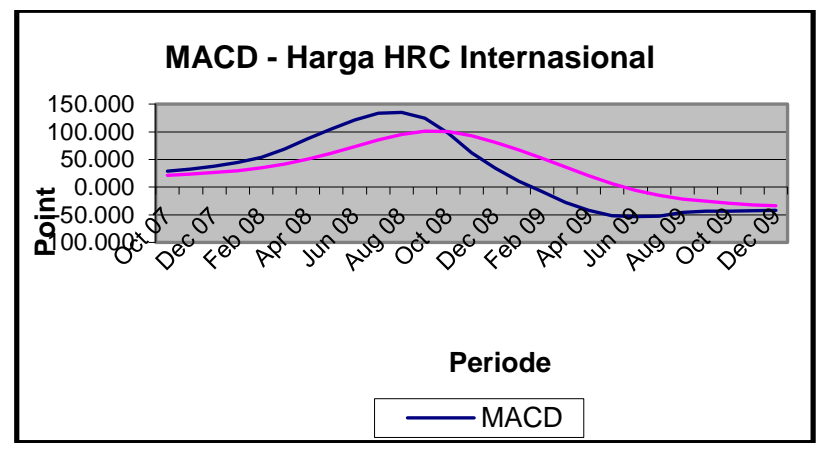

Gambar 2. Moving Average Convergence Divergence

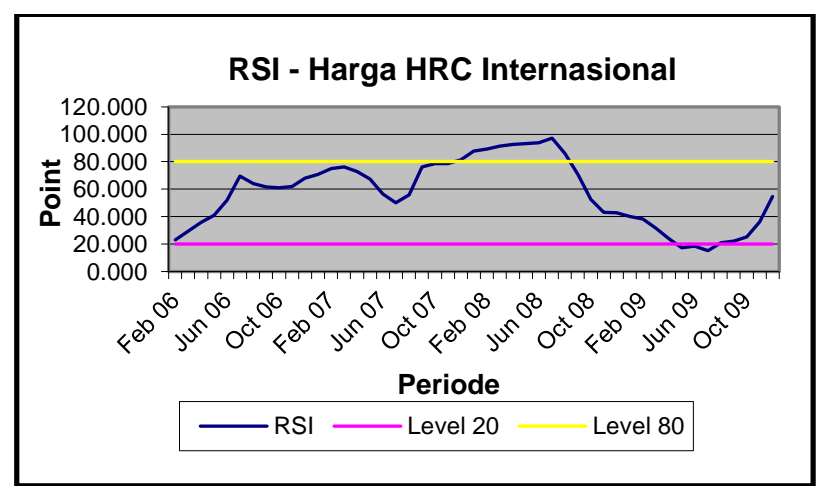

Gambar 3. Relative Strength Index
Pada grafik RSI terdapat tiga buah garis, yaitu garis level 20-80 dan garis RSI. Pada grafik garis level yang ditentukan adalah garis level 20-80 untuk meredam bad signal yang didapat dalam RSI.

Pada grafik RSI dapat ditunjukkan bahwa ketika bulan September 2008 garis RSI sudah menembus ke bawah garis level 80. Hal itu mengindikasikan bahwa harga akan turun, dimana harga dasar HRC internasional mulai turun secara tajam pada bulan Agustus 2008. Pada saat itu harga dasar HRC internasionl bulan Agustus 2008 mencapai harga US\$990 dan pada bulan September 2008 harga turun menjadi US $\$ 865$. Namun pada saat itu, harga dasar HRC PT. KS pada bulan Agustus 2008 mencapai harga US\$1214 dan pada bulan September 2008 harga dinaikkan menjadi US\$1236.

Dengan penggunaan metode RSI, PT. KS dapat memperoleh gambaran awal yang mengindikasikan bahwa akan terjadi perubahan pergerakan harga yang cukup drastis. RSI dalam hal ini dapat berperan sebagai "warning signal" dalam memprakirakan harga HRC internasional.

Pada prakiraan untuk bulan Januari 2010 belum ada indikasi perubahan pergerakan harga yang cukup signifikan yang ditunjukkan dalam grafik RSI. Dimana tidak ditunjukkan adanya garis RSI yang memotong garis level 20 ataupun garis level 80 .

Dari peramalan simulasi sistem dinamis dapat dilihat bahwa faktor-faktor yang mempengaruhi dari perubahan harga dasar HRC internasional adalah faktor permintaan (supply), faktor penawaran (supply), dan faktor lain seperti faktor kapasitas produksi dan faktor utilisasi produksi.

Simulasi yang dilakukan merupakan simulasi berdasarkan data pada bulan Januari 2009 dan digunakan untuk memproyeksikan harga HRC internasional yang akan terjadi pada satu setengah tahun ke depan yaitu sampai bulan Juni 2010.

Tujuan dilakukan simulasi ini adalah untuk memprakirakan harga dasar HRC internasional pada bulan Januari 2010 dan seterusnya. Namun, karena kurangnya data yang diperoleh, maka digunakan data dari bulan Januari 2009 untuk memproyeksikan harga dasar HRC internasional pada bulan Januari 2010 dan seterusnya.

Dari hasil yang diperoleh menunjukkan bahwa dalam pergerakan harga terjadi fluktuasi. Naik turunnya harga umumnya disebabkan oleh 
perbedaan antara supply dan demand. Jika supply sedang kekurangan dan demand sedang berlebihan maka umumnya harga akan naik, dan jika supply sedang berlebihan dan demand sedang kekurangan maka umumnya harga akan turun.

Adapun fluktuasi yang terjadi dapat disebabkan adanya lag di antara permintaan dan penjualan karena dalam konteks produksi baja, proses produksi yang dilakukan cenderung lama untuk memenuhi permintaan. Selain itu, waktu jeda untuk menginterpretasikan permintaan juga mempengaruhi fluktuasi dari harga HRC internasional ini.
Pada uji validitas model simulasi dihasilkan nilai U-Theil sebesar 0.009 yang artinya metode simulasi yang digunakan adalah lebih baik dibandingkan dengan metode naif. Hasil prakiraan harga HRC yang diperoleh dari metode simulasi ini adalah US\$517.9 pada periode Januari 2010, US\$543.61 pada periode Februari 2010, dan US\$565,10 pada periode Maret 2010. Prakiraan harga pada Januari 2010 sampai Maret 2010 adalah cenderung meningkat

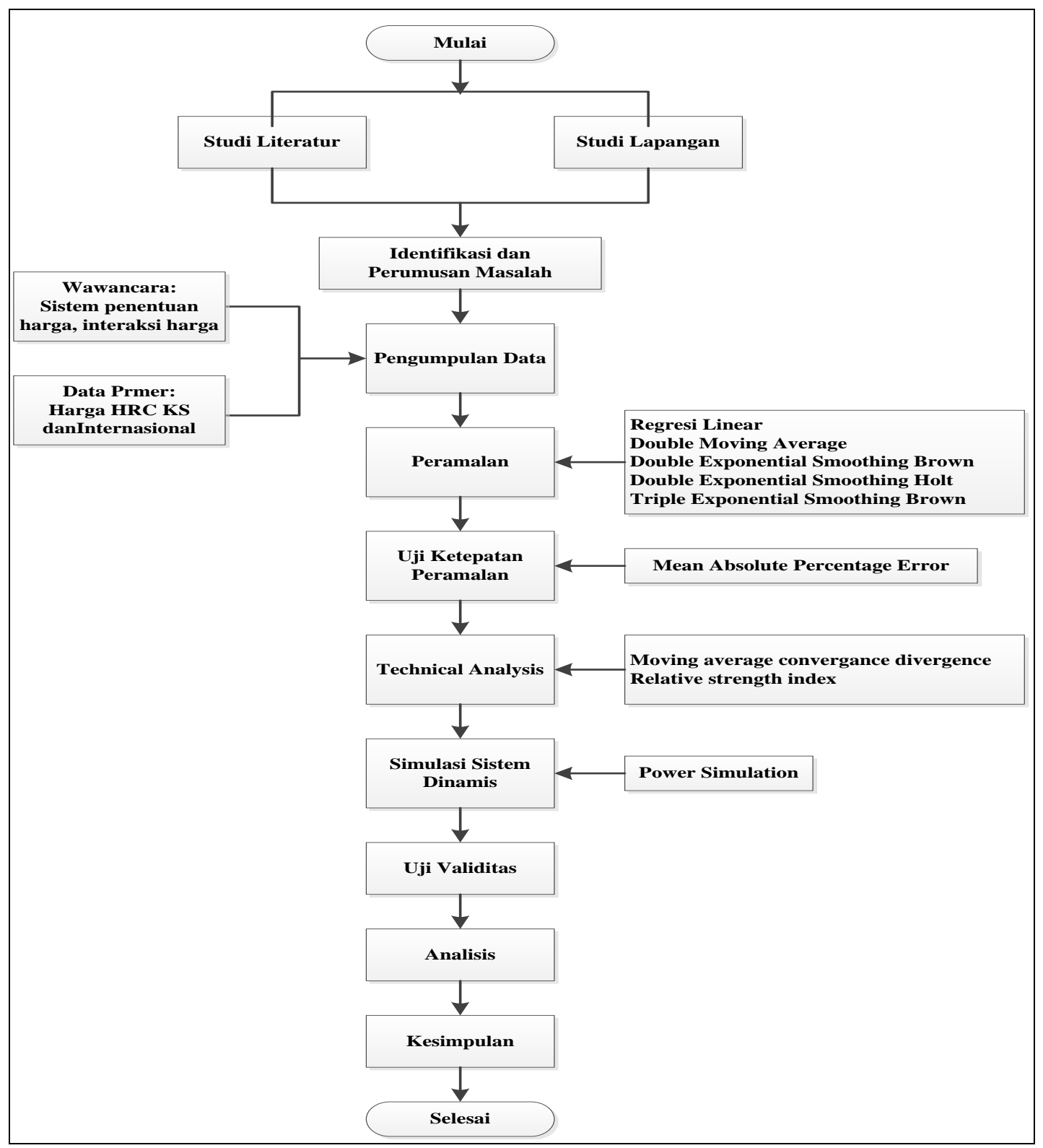

Gambar 1. Diagram Alir Metodologi Penelitian 


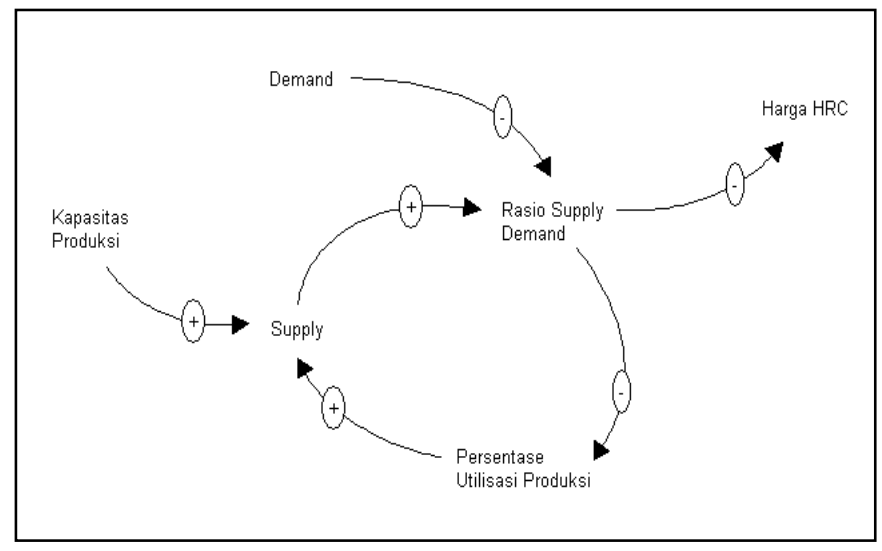

Gambar 4. Causal Loop Diagram

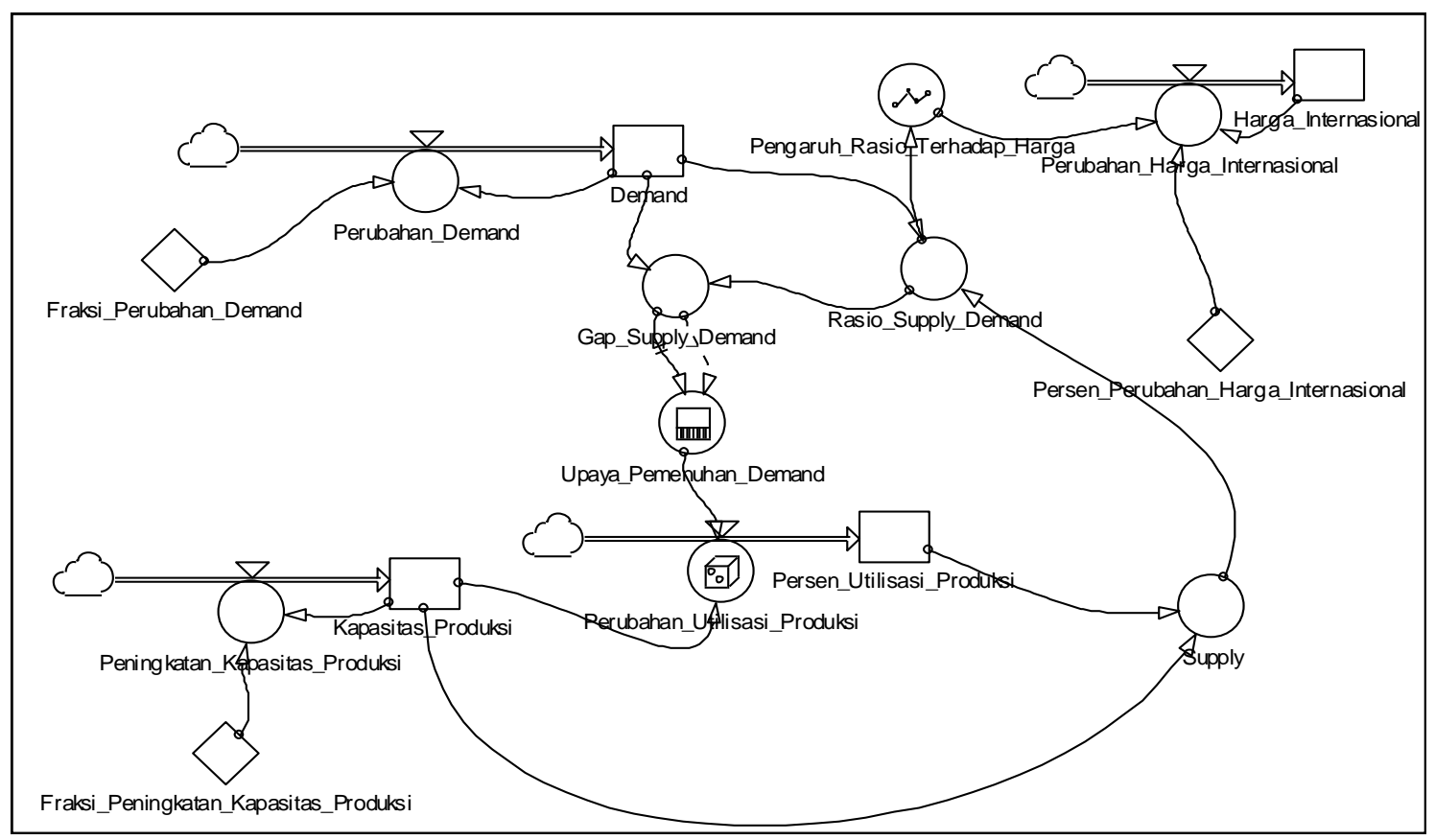

Gambar 5. Stock Flow Diagram

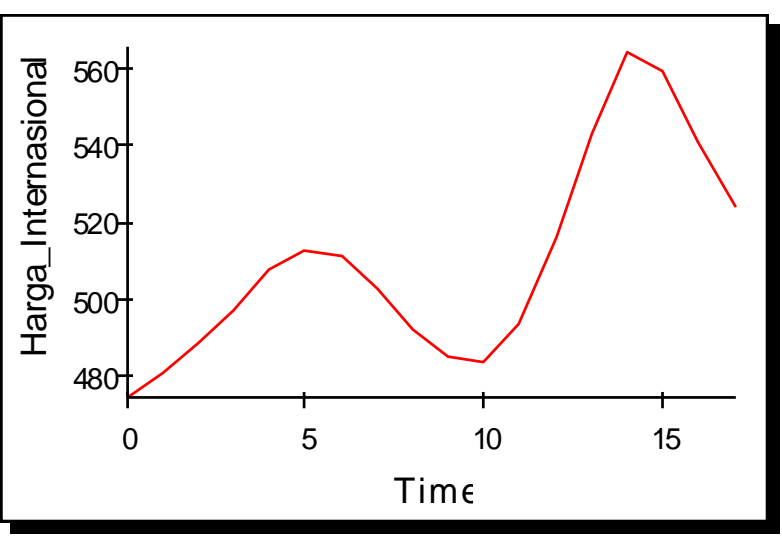

Gambar 6. Grafik Simulasi Harga Dasar HRC Internasional

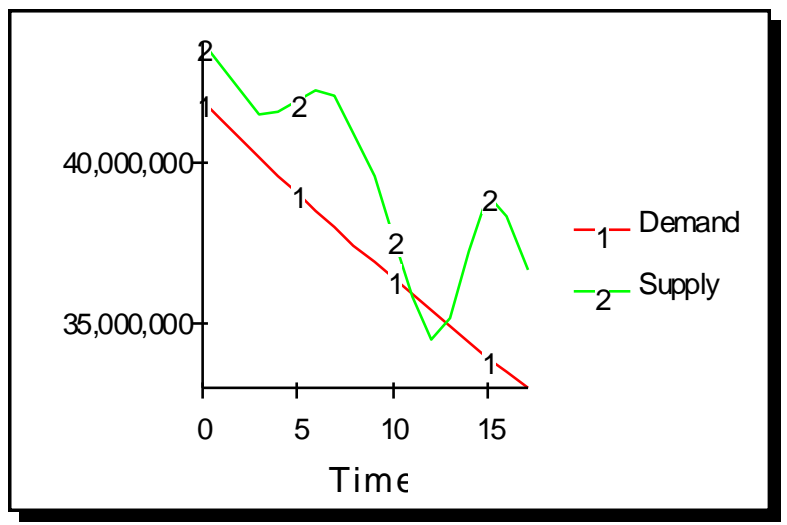

Gambar 7. Grafik Simulasi Supply dan Demand 
Tabel 3. Hasil Simulasi Sistem Dinamis Harga Dasar HRC Internasional

\begin{tabular}{|c|c|c|r|r|r|r||}
\hline Time & Demand & Supply & Rasio_Supply_Demand & Persen_Utilisasi_Produks & Harga_Internasional & \\
\hline 0 & $42,000,000.0$ & $43,800,000.0$ & 1.04 & 0.60 & 475.00 & \\
\hline 1 & $41,412,000.0$ & $43,117,167.5$ & 1.04 & 0.59 & 481.72 & 489.11 \\
\hline 2 & $40,832,232.0$ & $42,364,774.4$ & 1.04 & 0.579 & 497.91 \\
\hline 3 & $40,260,580.8$ & $41,582,431.4$ & 1.03 & 0.568 & 508.54 \\
\hline 4 & $39,696,932.6$ & $41,637,464.0$ & 1.05 & 0.568 & 513.53 \\
\hline 5 & $39,141,175.6$ & $41,982,031.0$ & 1.07 & 0.572 & 511.89 \\
\hline 6 & $38,593,199.1$ & $42,329,180.8$ & 1.10 & 0.576 & 503.56 \\
\hline 7 & $38,052,894.3$ & $42,170,128.4$ & 1.11 & 0.574 & 493.25 \\
\hline 8 & $37,520,153.8$ & $41,004,459.3$ & 1.09 & 0.557 & 486.28 \\
\hline 9 & $36,994,871.6$ & $39,688,670.1$ & 1.07 & 0.539 & 484.66 \\
\hline 10 & $36,476,943.4$ & $37,712,435.4$ & 1.03 & 0.511 & 494.65 \\
\hline 11 & $35,966,266.2$ & $35,883,039.9$ & 0.998 & 0.486 & 517.19 \\
\hline 12 & $35,462,738.5$ & $34,561,569.9$ & 0.975 & 0.468 & 543.61 \\
\hline 13 & $34,966,260.2$ & $35,232,413.3$ & 1.01 & 0.476 & 565.10 \\
\hline 14 & $34,476,732.5$ & $37,318,083.8$ & 1.08 & 0.504 & 560.29 \\
\hline 15 & $33,994,058.3$ & $39,081,050.7$ & 1.15 & 0.527 & 541.86 \\
\hline 16 & $33,518,141.5$ & $38,427,464.5$ & 1.15 & 0.518 & \\
\hline & & & & & & \\
\hline
\end{tabular}

\section{KESIMPULAN}

Untuk memprakirakan kecenderungan trend harga adalah dengan menggunakan metode relative strength index yang dapat mengindikasikan perubahan trend dengan lebih cepat. Untuk peramalan dengan menggunakan metode simulasi juga dapat digunakan untuk memprakirakan harga HRC, di mana nilai uji validitas dengan metode UTheil memperoleh nilai sebesar 0.009 .

Untuk bulan Januari 2010 diprakirakan harga dasar HRC akan berada pada kisaran US\$ 512 /ton sampai US\$ 551/ton, untuk bulan Februari 2010 diprakirakan harga dasar HRC akan berada pada kisaran US\$ 511/ton sampai US\$ 582/ton, dan untuk bulan Maret 2010 diprakirakan harga dasar HRC akan berada pada kisaran US\$ 512/ton sampai US\$ 609/ton.

Berdasarkan hasil RSI, dapat diperkirakan bahwa untuk awal tahun 2010 tidak akan terjadi perubahan harga dasar HRC secara drastis dan cenderung stabil dibandingkan kondisi harga dasar HRC saat akhir tahun 2009.

Faktor yang berpengaruh dalam perubahan harga dasar HRC adalah faktor kapasitas produksi, faktor persentase utilisasi produksi, faktor besarnya demand, dan faktor perbandingan antara supply dan demand terhadap produk HRC.
Usulan penentuan HRC dilakukan berdasarkan analisis peramalan, analisis perkiraan trend (RSI atau MACD), dan analisis dengan menggunakan teknik simulasi sistem dinamis.Hasil terbaik penentuan HRC adalah berdasarkan simulasi sistem dinamis.

\section{DAFTAR ACUAN / PUSTAKA}

[1] http://www.indexmundi.om (Diakses tanggal 20 Maret 2009).

[2] Makridakis; Wheelwright; McGee. Metode dan Aplikasi Peramalan, Edisi kedua, Jilid satu, Binarupa Aksara, Jakarta. 1999.

[3] Forrester, J.W. Industrial Dynamics. The MIT Press, Massachusetts. 1972.

[4] Muhammadi; Erman Aminullah; Soesilo, Budhi. Analisis Sistem Dinamis, UMJ Press, Jakarta. 2001.

[5] Sterman, John D. Business Dynamics : System Thinking and Modeling for a Complex Word, (International ed.) McGraw-Hill, Asia. 2004.

[6] Rosa Ma Mariz Perez; Ma Teresa Garcia-Alvarez. "A System Dynamics Model to Analyze The Influence of Financial Resources on The Percentage of Franchised Units", The International Business \& Economics Research Journal, Vol. 8, pp53. 2009. 